\title{
O DIREITO, O PODER E A VIOLÊNCIA: OBSERVAÇÕES SOBRE MEIOS E FINS SEGUNDO BENJAMIN E LUHMANN
}

\author{
THE LAW, THE POWER AND THE VIOLENCE: REMARKS ABOUT MEANS AND ENDS \\ ACCORDING TO BENJAMIN AND LUHMANN
}

RESUMO: Este artigo visa analisar a concepção de direito como meio ou fim, a partir das concepções de Walter Benjamin e Niklas Luhmann, atentando à forma como as categorias "poder" e "violência" são relacionadas ao Direito por ambos autores. Benjamin, estrutura seu pensamento a partir da ideia de direito como meio atrelado a "Gewalt", palavra alemã que significa ao mesmo tempo violência e poder institucionalizado, os quais são compreendidos a partir do seu papel para fundação ou manutenção do ordenamento. De modo distinto, Luhmann trata o Direito operacionalmente como um fim, uma vez que o considera como sistema elaborado pela comunicação, essencialmente dotado de autopoiese e autorreferência, ao mesmo tempo que também diverge quanto às ideias de poder (entendido a partir da generalização da seletividade sobre o agir) e de violência (marcada pela ausência desta seletividade). Assim, constata-se uma discordância teórica sobre o tema, que embora tratado de maneira distinta por tais teóricos possibilitam a compreender a aproximação entre os três elementos "direito", "poder" e "violência", sem esgotar a discussão sobre o papel ético deste primeiro como "meio" ou "fim".

PALAVRAS-CHAVE: Direito. Poder. Violência. Meios. Fins. Luhmann. Benjamin.

\section{Allan Jones Andreza* \\ Luciano Nascimento Silva ${ }^{* *}$}

ABSTRACT: This paper aims to analyze the conception of law as means or ends, based on the ideas of Walter Benjamin and Niklas Luhmann, having on mind how the categories "power" and "violence" are related to the law by both authors. Benjamin structure his thinking from the idea of law as means linked to "Gewalt", German word that means both violence and institutionalized power, which are understood by their role in the foundation or maintenance of order. Differently, Luhmann treats the law operationally as an end, since considers it as a system designed for communication, essentially endowed with autopoiesis and self-reference, and also diverges about the ideas of power (understood through the selective generalization about an act) and violence (marked by the absence of selectivity). Thereby, there has been a theoretical disagreement on the subject. Although treated differently by such philosophers, this debate allows an approach between these three elements: "law", "power" and "violence", without exhausting the discussion on the ethical role of the first as "mean" or "end".

KEYWORDS: Law. Power. Violence. Means. Purposes. Luhmann. Benjamin.

SUMÁRIO: Introdução. 1 O Direito, o poder e a violência consoante Walter Benjamin. 2. Direito, poder e violência conforme Niklas Luhmann. Conclusão. Referências.

\footnotetext{
* Mestrando em Ciências Jurídicas pelo Programa de Pós-graduação em Ciências Jurídicas da Universidade Federal da Paraíba (PPGCJ/CCJ/UFPB). Especialista em Direitos Fundamentais e Democracia pela Universidade Estadual da Paraíba (UEPB).

***ós-Doutorando em Sociologia e Teoria do Direito no Centro di Studi sul Rischio dalla Facoltà di Giurisprudenza dell'Università del Salento (CSR-FG-UNISALENTO). Doutor em Ciências Jurídico-Criminais pela Faculdade de Direito da Universidade de Coimbra (FDUC). Mestre em Direito Penal pela Faculdade de Direito da Universidade de São Paulo (USP). Professor da Universidade Estadual da Paraíba (CCJ/UEPB) e colaborador no Programa de Pós-Graduação em Ciências Jurídicas do Centro de Ciências Jurídicas da Universidade Federal da Paraíba (PPGCJ/CCJ/UFPB).
} 


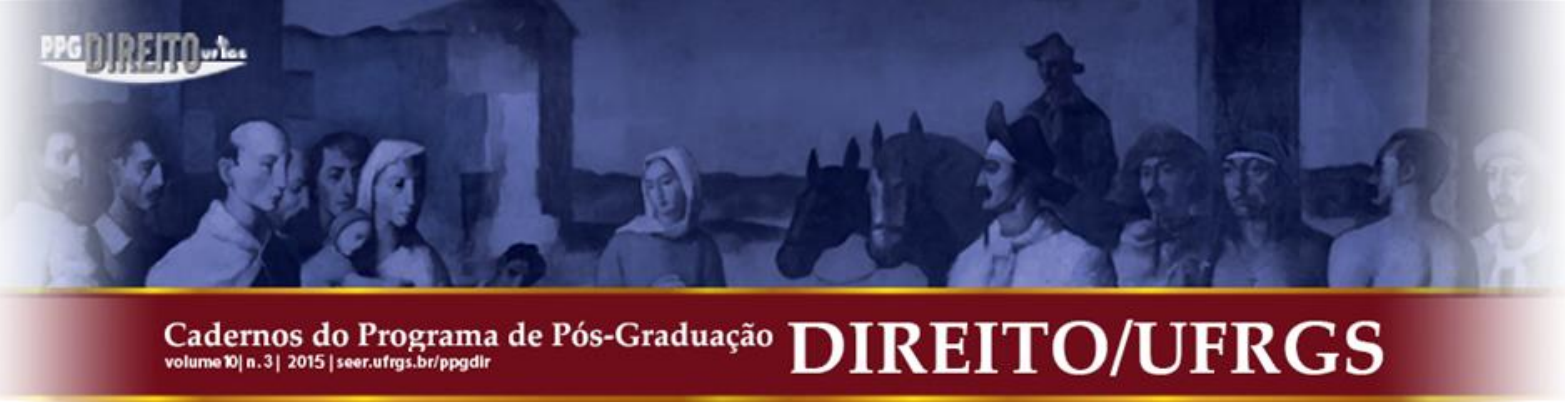

\section{INTRODUÇÃO}

Usualmente, as pessoas que iniciam seus estudos sobre o Direito utilizando os manuais introdutórios aprendem deste o princípio que a palavra "direito" pode ter várias acepções terminológicas, seja como ciência, seja como um conceito aproximado de justiça, entre outros $^{1}$, que possibilitam ao estudante uma incerteza conceitual frente a complexidade que de pronto se depara. Ao mesmo tempo, tal circunstância serve de subsídio para entender que a esfera do direito detém pontos ainda questionáveis, especificamente discordâncias teóricas, que verdadeiramente possibilitam uma gama de incansáveis estudos, sobretudo quando se adentra nos campos da filosofia e sociologia jurídica. Estas possibilitam a formulação de olhares discordantes sobre conceitos majoritariamente adotados, mas ao mesmo tempo possibilitam uma abertura cognitiva do Direito de modo a condicioná-lo a um processo de renovação estrutural e finalístico, de tal maneira que ele pode acabar exercendo influências diversas sobre as relações sociais e sobre outras ciências.

Por conseguinte, salienta-se que esta abertura possibilita a reformulação, a evolução ou o amadurecimento epistemológico, possibilitando ao Direito um importante aprofundamento teórico, como os questionamentos sobre sua condição ontológica e deontológica, pois possibilita pensá-lo enquanto sua essencialidade (ser) ou a partir de sua qualidade operativa (dever ser). Partindo destas considerações, sobrevém reflexões de ordem ética, especificamente a discussão sobre meios e fins aflora fundamentalmente para indagar sobre qual ponto desta discussão o Direito também pode ser identificado e ao mesmo tempo destacar ou qualificar o agir consoante suas prescrições.

Tais reflexões não podem ser destituídas da análise de elementos essenciais para o Direito, como as ideias de "poder" e "violência". De acordo com a abordagem teórica, estas categorias podem ser observadas como características estruturantes, mantenedora, presente apenas num segundo plano ou até mesmo esfaceladora do Direito.

Desta forma, questão elementar é a compreensão conceitual do Direito, o que possibilitaria chegar a duas conclusões: identificá-lo enquanto elemento constituinte de um

\footnotetext{
${ }^{1}$ Como exemplo, Nery (2008, p. 13) sinteticamente descreve algumas acepções do vocábulo direito como contrário do esquerdo, ordenamento ou norma, autorização ou permissão de fazer o que a norma não proíba, ou o que a norma autorize, qualidade do que atende a um anseio de justiça ou retidão, prerrogativa que alguém possui de exigir de outrem a prática ou abstenção de certos atos, ciência de norma coercitivamente imposta, conjunto de conhecimentos acerca dessa ciência, objeto da ciência do direito.
} 


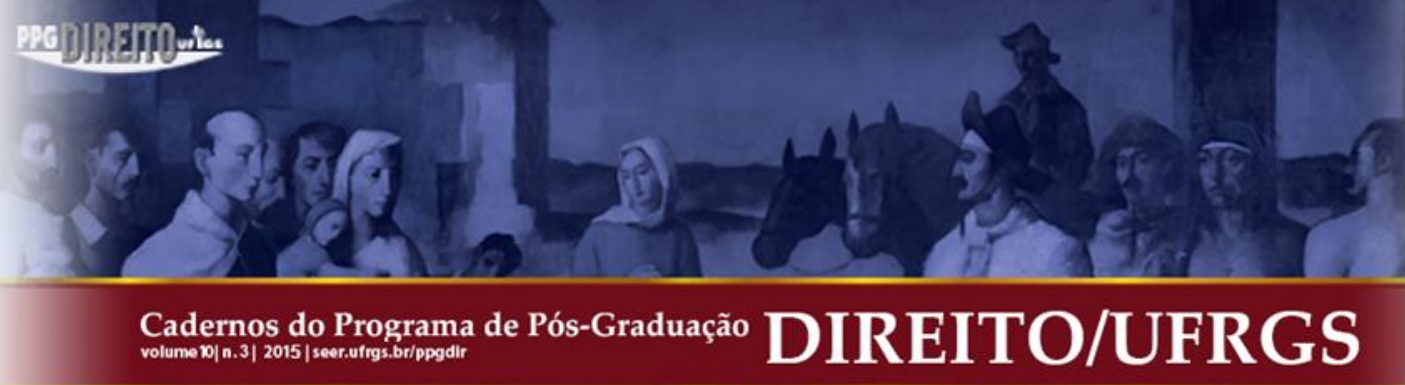

sistema autônomo, especificamente como um fim em si mesmo; ou até como meio para um determinado fim, o qual é, desta forma, por vezes associado a ideia de justiça. Logo, a ambígua concepção do Direito enquanto meio ou fim é o ponto de partida para este artigo que buscará tratar o tema esmiuçadamente, na mesma oportunidade em que possibilita pensar sob qual órbita situa a ideia de poder a ele atrelada.

Para atender esta expectativa, este artigo tratará os contrapontos existentes entre duas abordagens teóricas: de Walter Benjamin e de Niklas Luhmann, intencionando, para tanto, uma análise comparativa entre esses pensamentos que identificam o Direito como meio (primeiro) e como um fim em si mesmo (segundo).

O trato teórico perpassará as concepções de violência e poder utilizadas por tais teóricos, uma vez que a compreensão destes elementos segundo o enfoque destes pensadores, possibilita melhor entender como o direito utiliza da coerção do poder ou da violência para concretizar-se como fim ou como meio.

\section{O DIREITO, O PODER E A VIOLÊNCIA CONSOANTE WALTER BENJAMIN}

Inicialmente, conforme tratado por Benjamin (2013, p. 59), uma condição elementar para o Direito é a análise dos meios e dos fins, tal circunstância pressupõe uma questão ética, expressa numa série de questionamentos do tipo: os fins justificam os meios? A partir de tal consideração, outras perguntas podem ser alavancadas, como a violência e o poder se situam no âmbito dos meios para o exercício do direito? Se assim o for, eles podem ser utilizados para a garantia de fins injustos? E ainda melhor, a violência e o poder são meios necessários para a edificação do Direito? Se estes são meios, o Direito pode seria considerado um fim, ou também é um meio para se atingir um ideal de justiça? Neste caso, sob quais condições isso pode ser realizado? Deste modo, sob tantas perspectivas poder e violência poderiam ser considerados meio para atingir outro meio (direito), vislumbrando ao longe um fim?

Inicia-se tal debate a partir das análises de Walter Benjamin (2013, p. 60) quando este situa a discussão (sobre meios e fins) no âmbito da filosofia do direito, especificamente tratando sobre as diferentes abordagens desenvolvidas pelos direitos natural e positivo.

A partir de então, constata-se que o direito natural deita suas preocupações em fins tidos como justos, logo o exercício da violência e do poder seria uma condição aceitável para conquistar uma determinada finalidade que pela sua relevância (identificada pelo senso de 


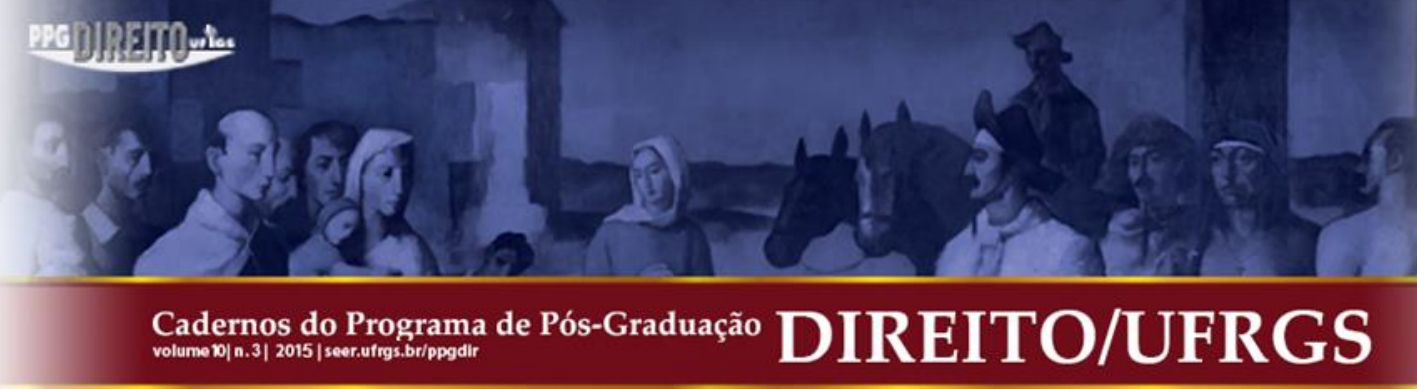

justiça) deteria uma importância superior aos bens jurídicos colocados em risco, prejudicados ou ameaçados, isso, por conseguinte, justificaria a aplicação de quaisquer meios, exceto se estes fossem utilizados injustamente, ou seja, se tais fins não fossem relevantes ao ponto de desculpar a utilização exacerbada ou desvirtuada destes meios.

Sob esta lógica, estar-se-ia diante de um argumento que, respeitadas as devidas proporções, se aproxima do utilitarismo. Note-se que este pensamento também utiliza o raciocínio de que os meios, ainda que violentos, seriam justificáveis caso possibilitassem um bem maior, o qual poderia corresponder a um valor consensualmente tido como superior ou que atendesse ao interesse de um maior número de pessoas, ou seja, garantisse um sentimento de bem-estar não apenas mais relevante mas também mais acessível.

Sob este prisma, há de se considerar a violência como um produto da natureza (BENJAMIN, 2013, p. 60), pois atenderia seus fins vitais, logo, enquanto meio, seria naturalmente legítimo. Salienta-se, contudo, que tal pensamento detém uma vagueza patente, porque os elementos essenciais por ele utilizados, tais como "justo", "adequado" e "relevante" tem conteúdo particularizado, ou seja, variam de acordo com as concepções subjetivas, num determinado momento histórico e espaço físico, assim, do ponto de vista jurídico, poderiam elevar a contingência das relações sociais abarcadas e também constituir uma medida responsável por formular um elevado grau de sensação de insegurança jurídica, haja vista que “O direito natural aspira a 'legitimar' os meios pela natureza justa dos fins" (BENJAMIN, 2013, p. 61). Notoriamente, a insegurança se situa nos dois pontos de tal premissa, tanto na ideia de meios (não há limites que determinem o que seria legitimamente aceitável), quanto na de fins (elemento de cunho valorativo de conteúdo variável, segundo concepções subjetivas ${ }^{2}$ ou, no mínimo, pontualmente indetermináveis).

Logo, é importante lembrar que, mesmo construindo um consenso social sobre o conteúdo e o valor de um determinado bem, de modo a estipulá-lo como fim essencial, ainda assim poder-se-á estar diante de uma problemática de grande complexidade, haja vista que outro valor igualmente considerado essencial, pode ser avaliado e confrontado com o primeiro, gerando um verdadeiro conflito. Exemplifica-se esta problemática quando do trato

\footnotetext{
${ }^{2}$ Sob esta perspectiva, aponta Kelsen (2001, p. 04): "O problema dos valores é, antes de tudo, o problema dos conflitos de valores. E esse problema não poderá ser solucionado com os meios do conhecimento racional. A resposta às questões que aqui se apresentam é sempre um juízo, o qual, um última instância, é determinado por fatores emocionais e possui, portanto, um caráter subjetivo. Isso significa que o juízo só é válido para o sujeito que julga, sendo, nesse sentido, relativo".
} 


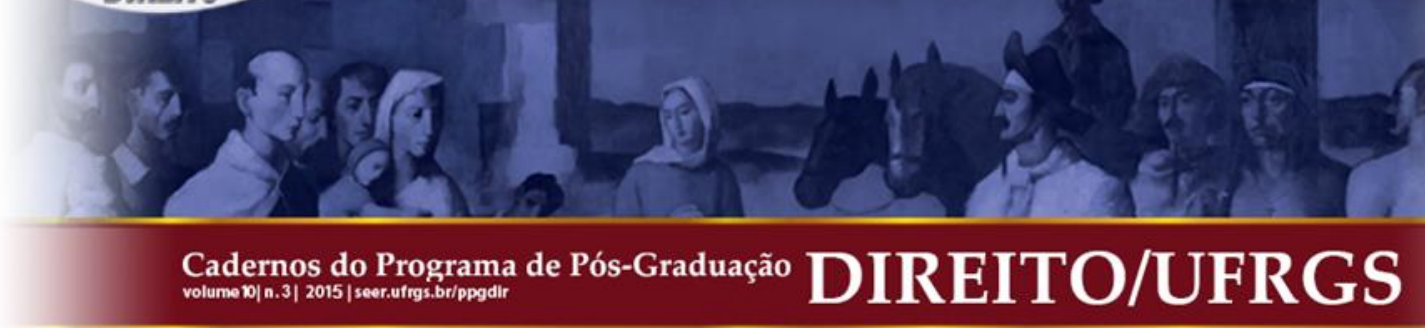

do homem-pessoa convivente e assim do homem no seu 'direito' e no seu 'dever' ou na sua responsabilidade.

No entanto, salienta-se que o direito positivo detém um cunho dualista, na medida que estabelece uma distinção básica: legitimidade ou não de seus meios, e é a partir desse interim que entende e classifica o que seja a violência segundo os pressupostos normativos, estipulando uma distinção entre violência historicamente reconhecida ou sancionada, e a não sancionada (BENJAMIN, 2013, p. 61).

Notório ainda salientar que ao mesmo passo que a violência seria objeto de classificações pelo direito, esta também é observada por Benjamin (2013, p. 66), ao tratar do militarismo, como instituidora do Direito e seu mantenedor, além de também ser reconhecida como um meio para atingir os fins do Estado ${ }^{7}$.

Assim, para compreensão do Direito, tomado sobretudo em seu aspecto deontológico, é determinado e fortalecido por um meio específico, o poder, e é sob esta perspectiva que afirma: "Na aplicação do poder sobre a vida e a morte, mais do que em qualquer outra aplicação da lei, é o próprio Direito que se fortalece" (BENJAMIN, 2013, p. 68). Por conseguinte, a categoria "poder", constitui elemento central do Direito, não apenas para sua instituição como também para sua manutenção ${ }^{8}$.

Sob este prisma, acaba sendo importante destacar que a ideia de violência utilizada por Benjamin detém um conteúdo muito aproximado da noção de poder ${ }^{9}$, pois ambas são meios que podem conduzir a criação ou manutenção do Direito, mesmo assim, ainda que de forma sutil, tal teórico as trata de forma diferenciada, na medida em que entende a violência como uma forma de poder, ou seja, há uma relação entre a espécie (violência) e o gênero (poder), inclusive por vezes utilizando expressões do tipo "poder-violência” (BENJAMIN, 2013, p.

\footnotetext{
${ }^{7}$ Logo, considerando-se as palavras de Benjamin (2013, p. 66), “(...) a violência mostra-se numa função totalmente diferente da do seu uso simples para fins naturais. Consiste no uso da violência como meio para fins jurídicos, pois a submissão dos cidadãos às leis - no caso vertente, a lei do serviço militar obrigatório - é um fim jurídico. Se àquela primeira função da violência chamamos a função instituidora do Direito, a segunda pode ser vista como função que o mantém".

${ }^{8}$ Segundo Benjamin (2013, p. 69), "Todo poder, enquanto meio, tem por função instituir o Direito ou mantê-lo". 9 Tal similitude encontra origem do ponto de vista semântico, haja vista que no texto original "Zur Kritik der Gewalt" a palavra "Gewalt" significa ao mesmo tempo "violência" e "poder", logo algumas traduções como Benjamin (1986, p. 160), possuem nota de rodapé introdutória alertando o leitor sobre este aspecto, inclusive ao ponto de informar: "A intenção de Benjamin é mostrar a origem do direito (e o poder judiciário) a partir do espírito da violência. Portanto, a semântica "Gewalt", neste texto, oscila constantemente entre esses dois pólos; tive que optar, caso por caso, se "violência" ou "poder" era a tradução mais adequada, colocando um asterisco quando as duas acepções são possíveis. (N.T.)". Neste interim, apesar de por vezes recorrer a comparações entre as duas traduções, este artigo tem como base a tradução mais recente, elaborada em 2013.
} 


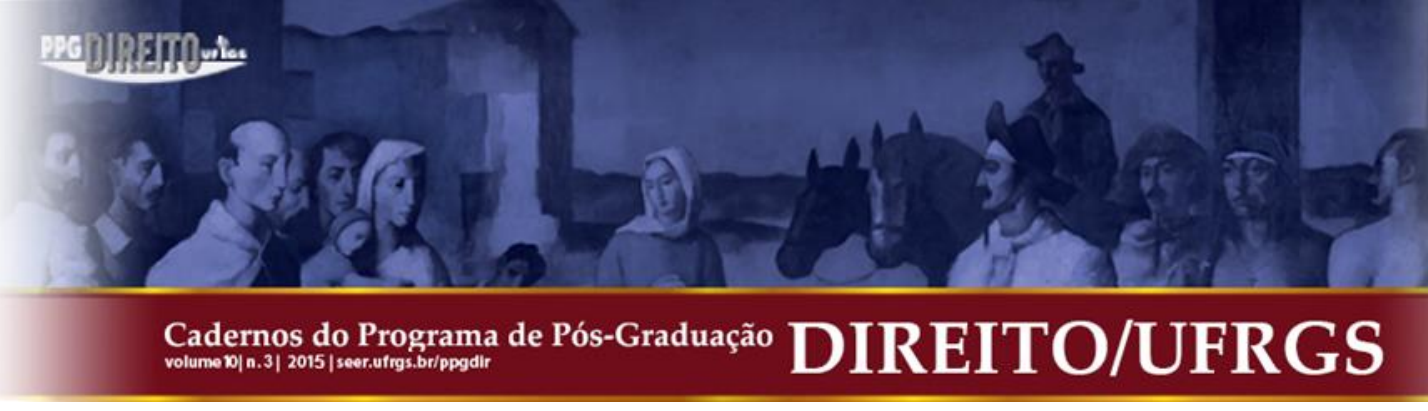

77). Logo, a violência constitui uma variação do poder, que é tratada como exercício carente de legalidade (como meio ilegal ou para-legal do exercício do poder) ou ainda como elemento coativo, voltado para a imposição de uma determinada circunstância à revelia dos interesses da outra parte da relação, ou seja, como uma ameaça, perspectiva esta que leva a compreender a violência como um mal necessário, capaz de ser utilizada para reclamar a violação de um contrato (por intermédio da possibilidade de sanção) ou mesmo para a própria inauguração deste contrato (a partir da estipulação de cláusulas e imposição de encargos para as partes contratantes), (BENJAMIN, 2013, p. 70).

Desse modo, a consciência da existência de uma violência tácita intrínseca ao direito é o que lhe dá sustentabilidade, pois "Quanto desaparece a consciência da presença latente de violência numa instituição de Direito, esta entra em decadência" (BENJAMIN, 2013, p. 69), por outro lado a aplicação da violência não apenas constitui um recurso para a manutenção do Direito, como também pode ser utilizada para propriamente instituir um direito novo e, assim, regular as relações sociais, influenciando diretamente distintas estruturas (economia, educação, etc.) de modo a fomentar o florescimento de uma nova realidade.

(...) a função do poder como violência na instituição do Direito é dupla, na medida
em que essa instituição se propõe ser aquilo que se institui como Direito, como seu
fim, usando a violência como meio; mas, por outro lado, no momento da aplicação
dos fins em vista como Direito, a violência não abdica, mas transforma-se, num
sentido rigoroso e imediato, em poder instituinte do Direito, na medida em que
estabelece como Direito, e nome do poder político, não um fim livre e independente
da violência, mas um fim necessária e intimamente a ela ligado. A instituição de um
Direito é instituição de um poder político e, nesse sentido, um ato de manifestação
direta da violência. (BENJAMIN, 2013, p. 77).

Para melhor elucidar as circunstâncias tratadas, Benjamin exemplifica citando o poder da polícia, este não apenas conduziria a manutenção do direito, por intermédio das ações desenvolvidas com a finalidade de garantir a proteção dos fins, ou melhor, bens por ele tutelados, como também possibilitaria instituir o direito, por decretar medidas com validade jurídica, necessariamente valendo-se das lacunas da leis para estipular um conteúdo jurídico específico em face das demandas que a própria polícia é chamada para intervir, desse modo o Direito é criado num momento específico, mediante uma rápida análise da realidade factual. Neste contexto é importante ressaltar que:

A afirmação segundo a qual os fins do poder policial seriam sempre idênticos aos do restante Direito, ou pelo menos ligados a eles, é absolutamente falsa. Pelo contrário, o "Direito" da polícia designa aquele ponto em que o Estado - seja por impotência, 


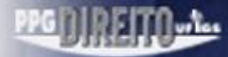

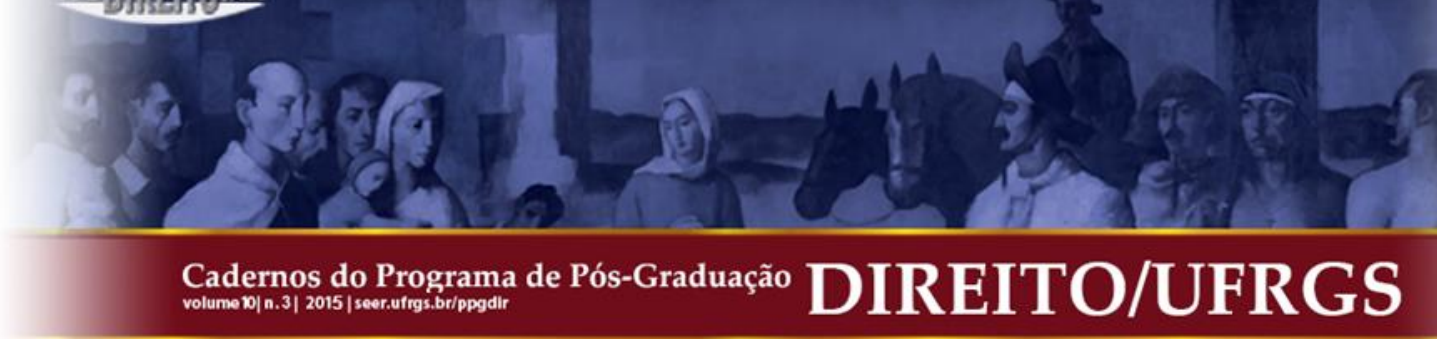

seja devido às ligações imanentes de toda a ordem jurídica - não está já em condições de garantir, através dessa ordem jurídica, os seus fins empíricos, que pretende atingir a qualquer preço. Por isso a polícia intervém em numerosos casos "por razões de segurança", quando a situação legal não é clara, para não falar dos casos em que, sem qualquer consideração de fins jurídicos, constitui um incômodo brutal que acompanha os cidadãos ao longo de toda uma vida regulamentada, ou para e simplesmente o vigia. (BENJAMIN, 2013, p. 69).

Assim, a polícia constitui uma instituição que se utiliza do poder, ora da violência, para a garantia do Direito, ora o instituindo, ou mantendo as instituições e mecanismos até então existentes. Desse modo, como única forma de garantir o Direito, tanto o poder quanto a violência prescrevem a impossibilidade de igualdade em suas relações, a não ser que haja um outro poder ou violência em mesma escala, que se confronte diretamente com a imposição anteriormente estipulada, ou até mesmo a subjugue.

Em perspectiva semelhante, Tobias Barreto, ainda em 1892, já detinha tal entendimento quando expõe "A serpe que não devora a serpe, não se faz dragão; a força que não vence a força não se faz direito; o direito é a força, que matou a própria força (...)" (BARRETO, 1892, p. 354). Compreende-se a partir das palavras do célebre jurista brasileiro que até para instituir-se como Direito este detém a necessidade de impor-se e do mesmo modo ocorre para manuter sua condição, por conseguinte, sua renovação ou alteração também deve basear-se num processo semelhante, de maneira que o Direito não se dissocia-se da ideia de força, a qual pode ser compreendida ora como poder ou ora como violência, de acordo com a previsibilidade jurídica do meio empregado ou de sua admissibilidade. Desta forma, segundo essa perspectiva, o Direito enquanto exercício de poder ou violência constituiria um meio para atingir finalidades defendidas ou protegidas por ele.

\section{DIREITO, PODER E VIOLÊNCIA CONFORME NIKLAS LUHMANN}

Antes de adentrar nas discursões propriamente ditas sobre direito e poder, é necessário tecer algumas considerações sobre a teoria de Luhmann, iniciando pelo apontamento de que este teórico é considerado "o mais relevante sociólogo do século XX” e tal posto se assenta na ideia de que sua concepção sociológica constitui mais do que uma teoria, verdadeiramente uma superteoria não-ontológica, que não se detém em descrever a sociedade, mas em explicar como as coisas funcionam ou são experimentadas. Isto faz com que sua teoria sirva de orientação para outras, contemplando um caráter de universalidade, e ao mesmo tempo não- 


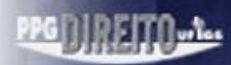

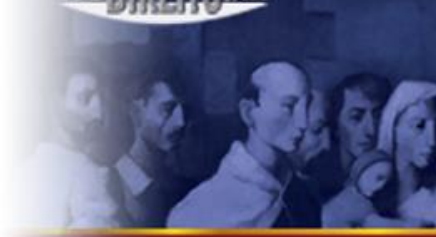 \\ Cadernos do Programa de Pós-Graduação volume D| n. 3 | 2015 | seer.ufrgs.br/ppgdir}

exclusivista, justamente por poder ser sustentada mesmo diante de outras descrições teóricas (ALBUQUERQUE, 2011, p. 92).

Ao tratar de um plano macrossociológico, Luhmann se utiliza da teoria dos sistemas sociais para descrever a funcionalidade da sociedade, sobretudo atentando as complexidades atuais, salientando que teoricamente a "comunicação" constitui uma categoria central (IZUZQUIZA, 1990, p. 24) a partir da qual partem os ensinamentos de tal pensador.

Logo, diante da amplitude teórica da sociologia Luhmanniana, tenta-se delimitar a abordagem teórica a ser tratada neste artigo a partir da análise das categorias "direito", "poder" e "violência" como elementos essenciais para entender em que pontos seu pensamento difere ou se aproxima das concepções de Walter Benjamin, bem como sob qual circunstância vislumbra o Direito, como meio ou como fim.

Para melhor compreender o que é o Direito, é importante assinalar algumas considerações sobre a teoria dos sistemas tratada por Luhmman. Izuzquiza (1990, p. 17), ao suscitar o pensamento luhmanniano informa que o conceito de sistemas sociais é utilizado como um pressuposto, não como uma finalidade, nem tão pouco constitui um limite explicativo, uma vez que a ideia de sistema não se circunscreve a um pensamento fechado, que viesse a proporcionar uma linearidade de argumentos, passíveis de esgotamento conceitual e superação paradigmática, pressupõe verdadeiramente as ideias de autorreferência e autopoiese. Esta última, é tida como a possibilidade de criar sua própria estrutura ${ }^{10}$, olhando para dentro, ou seja, a partir de um rearranjo das estruturas internas, sem perder a cognitividade sobre seu entorno, fazendo com que o mesmo seja fechado e aberto ao mesmo tempo, ${ }^{11}$ e que, por isso, o sistema não detenha um esgotamento, mas possa se auto reformular de acordo com as demandas as quais seja necessário intervir, constituindo, por conseguinte, um reiterado processo de diferenciação, sobretudo em relação ao meio ambiente. A partir de então, é importante salientar que a autopoiese se utiliza da autoreferrência para a reprodução das estruturas do sistema de maneira que ambos os processos são importantes para produzir a unidade do sistema e de seus limites (LUHMANN, 1996, p. 26).

\footnotetext{
${ }^{10}$ Conforme trata Luhmann (1994, p. 20), "Autopoiesis significa que um sistema reproduz os elementos de que é constituído, em uma ordem hermético-recursiva, por meio de seus próprios elementos. Isto ocorre ou não, de um momento para outro; não existem meias tintas ou terceiras possibilidades."

${ }^{11}$ Conforme será tratado posteriormente, Luhmann (1994, p. 20-21) indica que: “(...) o sistema jurídico opera simultaneamente sob premissas normativas cognoscitivas; está disposto a aprender e a não aprender, na medida da sua própria estrutura diferenciadora. É um sistema fechado e aberto: é fechado porque é aberto e aberto porque é fechado."
} 


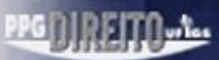 \\ Cadernos do Programa de Pós-Graduação volume $0 \mid$ | .3 | 2015 | seer.ufrgs.br/ppgdir \\ DIREITO/UFRGS}

Luhmann, sin embargo, recupera cuanto de positivo tiene el concepto de autorreferencia y hace del mismo um fundamento que possibilita que, a um tempo, el sistema posea clausura y apertura. Em tanto un sistema es autorreferente y autopoiético se encuentran, efectivamente, clausurado em sí mismo. Y sólo em tanto se encuentra así clausurado podrá constituirse como un sistema digno de atención y sujeto de un conjunto de operaciones específicas. Pero esta autorreferencia es, al mismo tempo, condición de la apertura del sistema. A un mayor nível de claura autopoiética y autorreferencia se da también un mayor nível de apertura del sistema. (IZUZQUIZA, 1990, p. 21)

Para entender tal racioncínio, é importante compreender que a sociedade é constituída graças à comunicação, uma vez que por intermédio desta é que se dá o relacionamento entre pessoas, e por conseguinte a formulação do sistema, que, conforme tratado, seria autorreferente, porque observa para dentro de si para reorganizar suas estruturas, as quais a partir de uma autopoiese permite que tal sistema vivencie um constante processo de diferenciação, que pode ser encarado hoje como o avanço da sua burocratização, expressa pela quantidade de subsistemas que expressivamente lhe compõe, tal como o direito, a economia, a política, a educação, entre tantos.

Para nuestro autor, la sociedad es un sistema autorreferente y autopoíettico que se compone de comunicaciones. A su vez, puede diferenciarse em distintos subsistemas, cada uno de ellos cerrado y autorreferente, que poseen un ámbito determinado de comunicaciones y de operación, que limitan su entorno y reducen la complejidad de un modo especializado. La sociedad se diferencia progresivamente, a lo largo de la evolución temporal y de la historia, em diferentes subsistemas socieales tales como el derecho, la economia, la política, la religión, la educación, etc. Y uma sociedad avanzada será siempre uma sociedad altamente diferenciada, em la que existan esos diferentes âmbitos de comunicación que son los diferentes subsistemas sociales. (IZUZQUIZA, 1990, p. 25)

Deste modo, é inicialmente sob este aspecto que Izuzquiza (1990, p. 18) chama a atenção para a diferença em relação ao conceito clássico de sistema, o qual é tido como "un conjunto de elementos que mantienen determinadas relaciones entre sí y que se encuentran separados de um entorno determinado". Veja, o conceito Luhmanniano não perde seu olhar sobre o ambiente, o que lhe confere relativo grau de abertura, mas ao mesmo tempo sua autorreferência lhe possibilita o fechamento necessário a garantir a aderência de suas estruturas, e é por intermédio de um processo de autopoiese que este sistema se diferencia no decorrer do tempo.

A diferenciação que o sistema social realiza do seu entorno tem como base a operação comunicativa, pois “(...) el término $<<$ sociedad $>>$ hay que entender el sistema que comprende 
todo tipo de comuncicaciones, que reproduce la comunicación por medio de la comunicación y de esta manera se distingue de un entorno". (LUHMANN, 1991, p. 26).

Baseado nesses pressupostos, pode-se compreender o direito como parte deste sistema social, ou seja, como um subsistema ${ }^{12}$, que por intermédio da comunicação cria generalizações ${ }^{13}$ congruentes de expectativas, o que costumeiramente trata-se como norma. A indiferença frente expectativas particularizadas constitui medida essencial para sua manutenção enquanto direito, sobretudo pela necessidade de se garantir a segurança de expectativas próprias para com a congruência das expectativas gerais ${ }^{14}$. Logo,

O Direito não é primariamente um ordenamento coativo, mas sim um alívio para as expectativas. O alívio consiste da disponibilidade de caminhos congruentemente generalizados para as expectativas, significando uma eficiente indiferença inofensiva contra outras possibilidades, que reduz consideravelmente o risco da expectativa contra-fática. A coerção relevante para o direito em termos constitutivos reside na obrigatoriedade de selecionar expectativas, a qual, por seu lado, em poucos mas importantes casos pode motivar imposição de determinados comportamentos. A necessidade de segurança que molda o direito se refere inicialmente à segurança das expectativas próprias, principalmente enquanto expectativas sobre expectativas, referindo-se apenas secundariamente à segurança do preenchimento dessas expectativas através do comportamento esperado. (LUHMANN, 1983, p. 115).

É a partir destas concepções que Luhmann (1983, p. 121) expressamente define o direito como “(...)estrutura de um sistema social que se baseia na generalização congruente de expectativas comportamentais normativas". Desta maneira, salienta-se que o Direito operativamente baseia-se na utilização de um código binário (jurídico/antijurídico), somente conhecendo esta operação como pertencente a este sistema (LUHMANN, 1994, p. 18).

De acordo com este contexto, Luhmann (1994, pp. 20-21) salienta que o direito não pode importar normas do ambiente, ou seja, para o mesmo não há um direito natural, nem tão pouco pode dar normas a este ambiente, uma vez que elas só existem dentro do sistema do

\footnotetext{
${ }^{12}$ Salienta-se que por várias vezes o Direito é tratado como sistema, mas é importante anotar que tal concepção é utilizado para considerar sua operacionalidade, enquanto autopoiético. Uma vez que o mesmo deve ser considerado dentro do sistema social.

${ }^{13}$ Segundo Luhmann (2006, p. 48), "Os meios de comunicação simbolicamente generalizados só surgem no momento em que a técnica de difusão permite ultrapassar os limites da interacção entre os presentes e programar informações para um número desconhecido de sujeitos ausentes e situações que não se conhecem ainda com exactidão".

${ }^{14}$ Conforme tratado por Luhmann (1994, p. 20), “(...) uma expectativa tem uma pretensão normativa, se sua comunicação promete que dita expectativa será mantida mesmo em caso de desilusão. Isto é somente a manifestação de uma intenção subjetiva. O direito se produz, então, pela seleção e generalização de semelhantes pretensões normativas. Estas são válidas ao serem aceitas por outros, ao perdurarem, ou seja, quando podem ser repetidas em outros casos e formalizadas de maneira geral e relativamente livre do contexto. A semântica do "dever" simboliza o resultado de semelhante processo de generalização."
} 


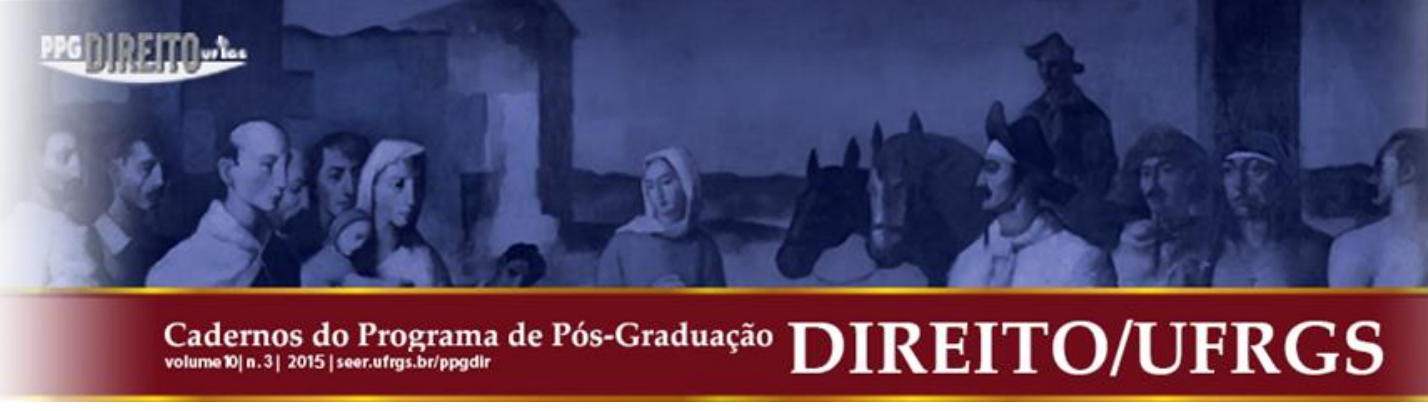

direito, haja vista que a normatividade é processo que o mesmo utiliza para se operacionalizar. No entanto, é importante atentar que o sistema tem cognitividade aberta para o ambiente, proporcionando ao mesmo que se oriente em relação ao seu ambiente. Isso ocorre quando o sistema se confronta com desilusões frente as expectativas, momento este que a cognitividade promove um processo de aprendizagem, ou seja, estipula uma expectativa substitutiva responsável pela sua "adaptação" ao ambiente. Assim, o sistema jurídico deve ser encarado, ao mesmo tempo, como fechado e aberto. Fechado do ponto de vista normativo, mas aberto a partir do aspecto de sua cognitividade frente ao ambiente. E essa oscilação entre estas duas circunstâncias que sustenta sua diferenciação.

Luhmann (1983, p. 122) acrescenta ainda que o seu

(...) conceito de direito contém, assim, elementos constantes e variáreis. Como uma constante temos a função da generalização congruente, que tem que ser de alguma forma preenchida em toda e qualquer sociedade humana. Evolutivamente variável, por outro lado, é o grau de diferenciação dos mecanismos do direito, e com isso também o grau em que se formam estruturas e processos correspondentes ao conceito de direito.

Assim, tal concepção é importante para compreender o direito não apenas a partir da norma, relegando a decisão judicial à pura reprodução simbólica da norma, mas a partir da concepção que esta forma de comunicação produz e conduz a adequação das expectativas particulares à sua disposição, que encontra validade na norma, que por sua vez detém como raiz de sua validade a vinculação social, ou seja, a generalização decorrente da própria decisão judicial, que assim intervém no mundo concreto, por intermédio de processo autorrecursivo de validade, conforme o próprio Luhmann (1994, p. 21) indica:

Para recombinação contínua de reprodução fechada e orientação ambiental aberta,
ou seja, de modelos normativos e cognoscitivos de expectativa, o sistema jurídico
dispõe de duas formas de comunicação: decisões e argumentos. Decisões
juridicamente vinculantes produzem-se quando o sistema jurídico utiliza a
capacidade do sistema político de impor decisões coletivamente vinculantes, mesmo
em caso de resistência. A integração da capacidade de aprendizagem se realiza aqui
mediante programas de decisão, que adaptam sua aplicação às circunstâncias de uma
situação concreta. Se isto não for suficiente, se prevê também a variabilidade dos
programas de decisão, e e chega finalmente ao princípio da positividade do direito.
O direito é válido, então, em razão de decisões que estabelecem sua validade. O
próprio sistema jurídico há de acreditar nesta razão de validade.

Neste interim, compreende-se que o direito se reproduz por um processo autopoético, a partir de seu rearranjo estrutural, fazendo com que se reorganize, estruture os seus próprios fundamentos que servem de base para suas decisões, as quais criam ou reforçam estes

Cadernos do Programa de Pós-Graduação em Direito PPGDir./UFRGS | Edição Digital | Porto Alegre | Volume XI | Número 1 | 2016 | P. 317-339 


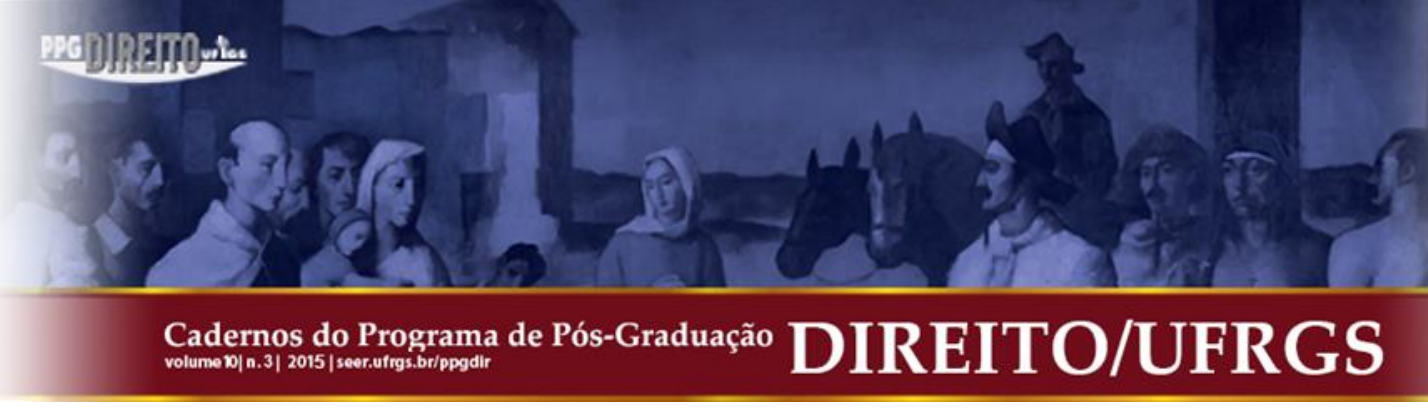

mesmos fundamentos. Ao mesmo tempo, é importante considerar que, por tratar-se de um sistema autorreferente e autopoético, o Direito não perde a expertise conquistada por intermédio das experiências passadas, mas as utiliza como um processo de aprimoramento, assim o mesmo acaba se auto utilizando para possibilitar sua diferenciação, verdadeiramente é como se funcionasse como um "meio" para os "fins" que ele próprio elege e, por conseguinte, o faz ser compreendido como um "fim em si mesmo", mas não pelos valores que, sob o ponto de vista ontológico ou deontológico, carrega, tal como a doutrina clássica identifica o direito natural, mas pela sua operacionalidade. Sob esta circunstância é importante lembrar as palavras de Luhmann (1994, p. 28):

O direito se reproduz como direito, e não como ciência. A reprodução se realiza no
âmbito dos acontecimentos fáticos elementares, no âmbito da comunicação de
momento a momento. Isto requer um mínimo esforço estrutural, mas não, ou apenas
em raras ocasiões, reflexão. Ao aumentar a complexidade, o direito pode
desenvolver técnicas para correlacionar casos similares, reencontrar decisões prévias
semelhantes, armazenar tópica ou conceitualmente experiências convincentes;
sobretudo, devido à formação das novas gerações, é capaz de desenvolver fórmulas
de aprendizagem e dogmática mais sistematizadas, que podem englobar, cada vez
mais, casos distintos num princípio.

Partindo da concepção de Luhmann (1994, p. 22) sob redundância, que segundo este seria a ligação entre argumentos a partir de conhecimentos comuns, que lhe reduziria o "valor informativo (efeito surpresa)" originando um processo de sobreposição, a decisão judicial teria maior sustentabilidade de acordo como o jurista aumenta ou diminui esta redundância, pois o uso exacerbado de argumentos redundantes pode, ao mesmo tempo dar maior força retórica, mas também pode inferir a perceptibilidade de implicativos além dos desejados, ao mesmo tempo a carência de informações redundantes pode ensejar o aumento da seletividade comunicativa, pois sob esta circunstância proporcionará a incompreensão imediata da comunicação fazendo com que o observador necessite buscar meios ou recursos além dos conhecimentos que já possua para entendê-la.

A partir de então, é importante situar a concepção Luhmanniana de "poder" e "violência", sobretudo para possibilitar entender a diferenciação teórica que estabelece em relação a Walter Benjamin. Neste interim, salienta-se que já nas palavras iniciais do seu livro, intitulado "Poder", Luhmann faz severas críticas as visões tradicionais do termo, as quais se utilizam de uma abordagem descritiva ou casuística, uma vez que, segundo o mesmo, tais 


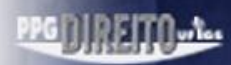

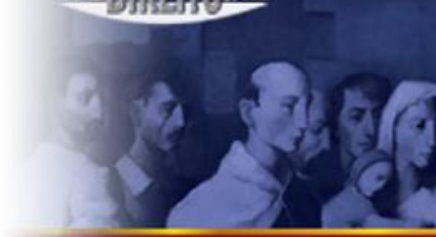 \\ Cadernos do Programa de Pós-Graduação volume D| n. 3 | 2015 | seer.ufrgs.br/ppgdir}

concepções baseiam-se em suposições ou até mesmo em análises de pontos isolados (LUHMANN, 1985, p. 03).

Tal crítica irá dar ensejo a uma visão particularizada de "poder" a ser elaborada por Niklas Luhmann, na medida em que o entende como elemento presente nas relações de comunicação social, identificando a sociedade como condição de sua possibilidade de existência (LUHMANN, 1985, p. 04). A efetivação desta comunicação ocorre quando um receptor compreende a seletividade de uma mensagem, por conseguinte o poder se manifesta quando há uma redução da insegurança na transmissão da informação, a partir não só da compreensão, mas da reprodução da seletividade, ou seja, decorre da aptidão para influenciar a seleção de ações ou omissões, o que é feito a partir de um processo de generalização e simplificação que proporcionará a redução das contingências e complexidades.

Um pressuposto fundamental de todo poder é, pois, que, no que se refere à seleção do poderoso Alter, existe insegurança. Alter dispõe, pela razão que for, de mais de uma alternativa. Ele pode, com respeito à escolha a ser feita pelo parceiro, gerar e superar, nele, insegurança. Esta passagem pela produção e redução da insegurança é um pressuposto específico do poder, condição do espaço de generalização e especificação de um meio de comunicação particular - e não uma fonte qualquer de poder entre outras. (LUHMANN, 1985, p. 08-09).

Essa influência e simplificação da seletividade constitui um elemento fundamental para a existência/manifestação do poder, pois o uso de coação reduz a seletividade a zero ou uma consequentemente violência física impõe a substituição do agir particular pela mera reprodução do agir do outro (LUHMANN, 1985, p. 09).

Em contraposição, haverá a elevação do poder quando este determinar uma seletividade frente as crescentes alternativas do poderoso ou do subordinado, deste modo “(...) O poder cresce com liberdades de ambos os lados; ele aumenta, por exemplo, numa sociedade, na medida em que gera alternativas" (LUHMANN, 1985, p. 09) e quanto mais improvável a realização do resultado almejado, maior será sua manifestação, o que ocorre também quando a disseminação desta seletividade, a partir de um processo de reprodução/ generalização, verdadeiramente constitui uma cadeia de ações. Deste modo, o poder demonstra sua funcionalidade para a regulação das contingências e redução das complexidades ${ }^{15}$.

${ }^{15}$ Conforme menciona Simoni (2008, p. 156), “o exercício de atos de poder acontece na forma de um tipo especial de comunicação que vincula as comunicações ulteriores de um modo muito mais sutil (...) A obediência ao poder, nessa perspectiva teórica, está na própria seletividade de uma forma especial de comunicação que vincula".

Cadernos do Programa de Pós-Graduação em Direito PPGDir./UFRGS | Edição Digital | Porto Alegre | Volume XI | Número 1 | 2016 | P. 317-339 


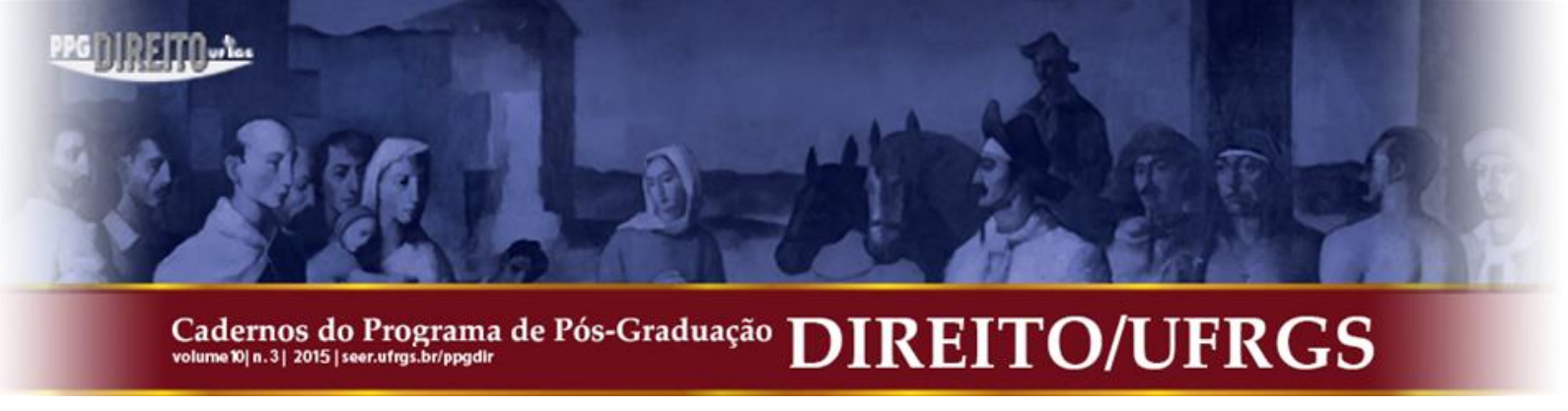

Apesar da distinção, violência e poder não constituem, para Luhmann, elementos de todo apartados, conforme lembra Albuquerque (2012, p. 220):

Para a teoria da comunicação simbolicamente generalizados, a violência (Gewalt, algumas vezes physische Gewalt) é o símbolo simbiótico vinculado ao poder. Tratase, portanto, de uma representação simbólica do embate físico entre seres humanos, relacionado ao conflito. O embate em si não é descrito como comunicação, mas praticamente como ausência dela; (...) Sendo, assim, os sistemas sociais tendem a excluir o embate físico, rejeitando a violência em seu interior ou, mas especificamente, incluindo-a apenas no caso da violência legítima.

Ao longo de sua evolução, o poder foi relacionado com a violência legítima, com a inclusão daquela mesma violência que fora excluída, de modo a garantir a efetividade da exclusão. (...) Assim, por volta do século XIX, a capacidade de impor-se fisicamente surge semanticamente como requisito de um Estado. LUHMANN vê nessa concentração de meios de violência um evento evolutivo: o conflito violento é a variação, o Estado territorial concentrando a violência, a seleção estabilizada. O poder político, como meio de comunicação simbolicamente generalizado emerge, então, vinculado A violência legítima (incluída, capaz de produzir comunicação) e se torna a alternativa que compõe a comunicação pelo poder.

Assim, Luhmann não apenas distingue poder e violência, como também define uma ligação entre ambos, ainda que esta seja uma alternativa a ser evitada ${ }^{18}$, está presente no poder como situação limite, exercida por mecanismos simbióticos, uma vez que opera tanto no campo simbólico como orgânico ${ }^{19}$.

Neste contexto é importante ressaltar que, ao tratar da fundamentação do direito, especificamente do papel que a violência exerce em sua composição histórica, Luhmann (2014, p. 27) informa:

(...) a origem na violência não é compreendida como uma tese histórica que não tenha nada a ver com a atualidade. Se se interpretasse historicamente a tese da origem do direito na violência, isto conduziria somente à auto-referência, quer dizer, à concepção de que o direito, à medida em que se distanciasse de sua origem, deveria constituir-se em origem de si mesmo. Não obstante, a violência é um contínuo fenômeno secundário do direito, ainda que externo.

Dentro do código bruto do meio (poder/não-poder), o não-poder, não é o valor de preferência porque a comunicação não poderá continuar mediante essa negação".

18 Conforme assenta Luhmann (1985, p. 52): “A violência empregada intencionalmente contra homens é ordenada ao poder, como meio em relação ao agir, por eliminar o agir pelo agir, excluindo assim também uma transposição comunicativa das premissas reduzidas da decisão. Com estas propriedades, a violência física não pode ser poder, mas é o caso limite intransponível de uma alternativa a evitar constitutiva do poder." (Grifo do autor)

19 "El poder se reproduce sólo en la forma directa de la obediencia. El medio correpondiente para la sanción es la fuerza física, que debe ser utilizable de manera generelizada, y que constituye también el mecanismo (o símbolo) simbiótico del poder. Sin embargo, el poder está simbolizado: los símbolos permiten tanto determinar e imponer decisiones (se deve hacer de esta manera, por éste y aquel motivo) cmo hacer posible el poder (desfiles, banderas, etcétera). El aspecto comunicativo sea sólo una amenaza, por el hecho de que de cualquier manera deve ser decidido.” (CORSI; ESPOSITO; BARALDI, 1996, p. 126). 


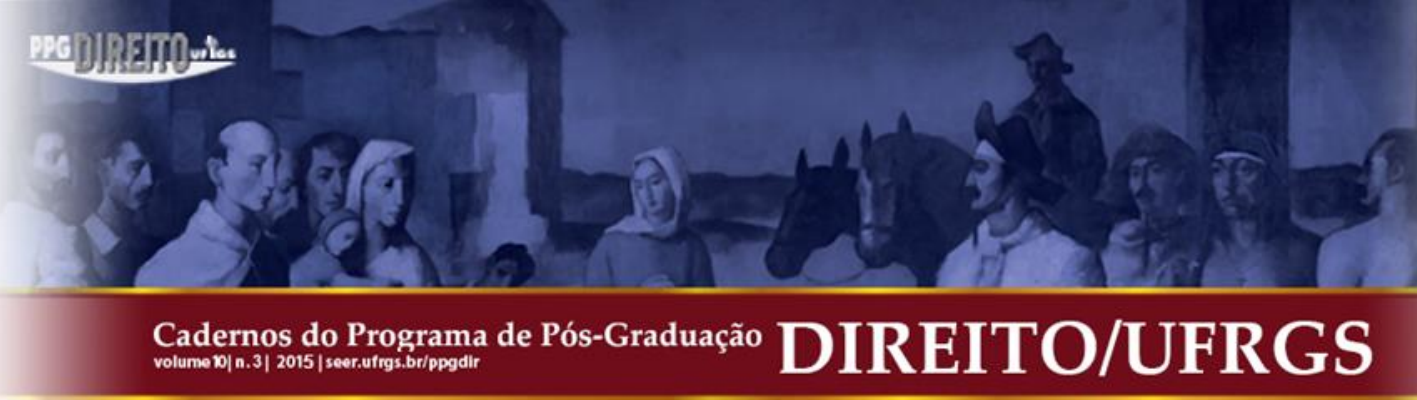

entre meios e fins no âmbito jurídico e do papel do poder e violência para a composição estrutural da teoria jurídica.

Primeiramente, é importante destacar o posicionamento diametralmente oposto sobre a constituição do direito para tais autores, enquanto Benjamin vislumbra o poder (com conceitualmente aproximado da ideia de violência institucionalizada) como elemento vetor do Direito, para Luhmann a comunicação seria o elemento constitutivo do Direito, o qual é visto como sistema autorreferente e autopoiético, capaz de promover sua diferenciação em relação ao ambiente, ou seja, sua distinção quanto ao seu entorno.

Ao mesmo tempo, constata-se que sobre o ponto de vista operativo, o Direito para Benjamin constitui um meio para se atingir os fins juridicamente relevantes, ou seja, definidos pelo direito positivo, enquanto que para Luhmann, o Direito seria um sistema que tem como base a generalização de expectativas congruentes e que se utiliza da autorreferência para se reformular e de uma abertura cognitiva sobre o ambiente para evoluir/adequar-se estruturalmente por intermédio de um processo de autopoiese, logo sobre esta perspectiva o Direito opera como um fim em si mesmo, sistematicamente utilizando-se da comunicação e, vinculado a esta, do poder para desenvolver a estabilização das complexidades.

Neste contexto, apesar de constituir um ponto comum entre as teorias em análise a existência de certo liame presente entre "violência", "poder" e "direito", ressalva-se a diferenciação conceitual destes elementos e distinção teórica que tratam a relação entre poderviolência e direito. Enquanto que, para Benjamin violência e poder possuem conteúdo aproximado e estão relacionados à força coativa legitimada e institucionalizada pelo Direito para o exercício dos interesses que lhes são próprios, garantindo-se a proteção dos fins juridicamente relevantes, o que, por conseguinte, faz entender a relação entre o poderviolência e o Direito como um mutualismo, vislumbra-se diametralmente distinta a concepção utilizada por Luhmann, para quem a definição de poder parte da generalizada seletividade proporcionada pela comunicação, de forma que a ausência desta seletividade caracteriza a violência.

Sob o ponto de vista estruturante do Direito, a violência, para Luhmann, assume um papel secundário, presente sobretudo na sanção ou mesmo na ameaça a imposição desta, apesar de constituir uma situação limite a ser evitada, cuja legitimidade assenta na própria comunicação desenvolvida pelo sistema jurídico. 


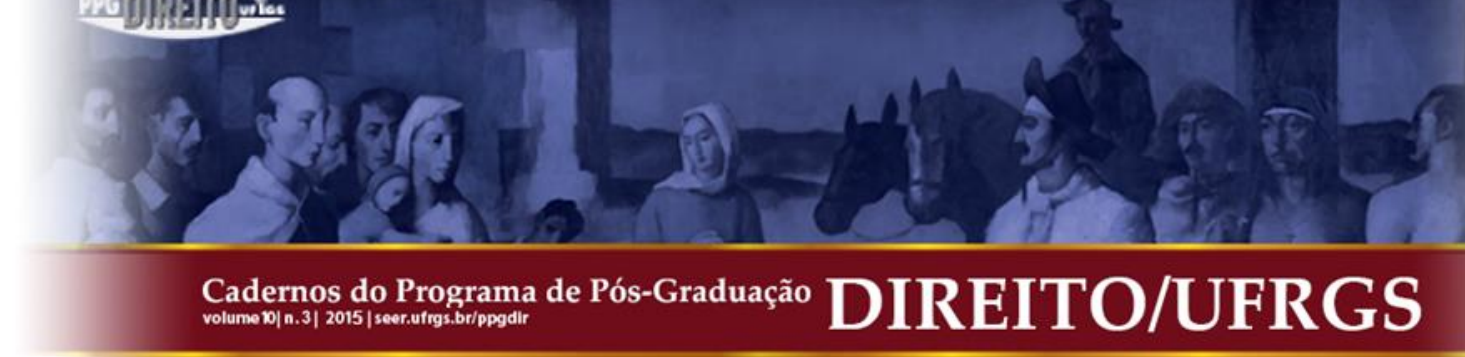

KELSEN, Hans. $O$ que é a justiça? A justiça, o direito e a política no espelho da ciência. Tradução de Luiz Carlos Borges. 3. ed. São Paulo: Martins Fontes, 2001.

LUHMANN, Niklas. Sociologia do Direito I. Tradução de Gustavo Bayer. Rio de Janeiro: Edições Tempo Brasileiro, 1983.

. Poder. Tradução de Martine Creusort de Rezende Martins. Brasília: Editora Universidade de Brasília, 1985. (Coleção Pensamento Político. 73).

. Límites de la comunicación como condición de evolución. Revista Occidente. n. 118, 1991, p. 25-44.

. O enfoque sociológico da teoria e prática do Direito. Sequência: Estudos Jurídicos e Políticos. Florianópolis, jan. 1994, p. 15-29. ISSN 2177-7055. Disponível em: $<$ https://periodicos.ufsc.br/index.php/sequencia/article/view/15871>. Acesso em: 26 out. 2015.

La ciencia de la sociedad. Traducción de Silva Pappe, Brunhilde Erker, Luis Felipe Segura; bajo la dirección de Javier Torres Nafarrate. México: Universidad Iberoamericana, 1996. (Autores, textos y temas. Ciencias Sociales; 10).

. A improbabilidade da comunicação. Lisboa: Edições Vega, 2006.

NERY, Rosa Maria de Andrade. Introdução ao pensamento jurídico e à teoria geral do Direito Privado. São Paulo: Editora Revista dos Tribunais, 2008.

NEVES, António Castanheira. Entre o legislador, a sociedade e o juiz ou entre sistema, função e problema - os modelos actualmente alternativos de realização jurisdicional do Direito. Boletim da Faculdade de Direito da Universidade de Coimbra. v. LXXIV (separata). Coimbra, 1998.

NUSSBAUM, Martha C. Las fronteiras de la justicia. Consideraciones sobre la exclusión. Traducción de Ramon Vilà y Albino Santos Mosquera. Barcelona: Espasa Libros, 2012.

RAWLS, John. Uma teoria da justiça. Tradução de Vamireh Chacon. Brasília: Editora Universidade de Brasília, 1981. (Coleção Pensamento Político, 50). 


\section{Nablingrim

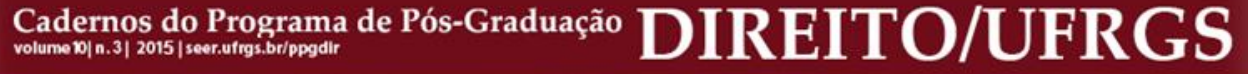

REALE, Miguel. Lições Preliminares de Direito. 27. ed. São Paulo: Saraiva, 2005.

SIMONI, Rafael Lazzarotto. A Comunicação do Poder em Niklas Luhmann. Revista Brasileira de Estudos Politicos. n. 97, Belo Horizonte, jan./jun. 2008 p. 153-178. Disponível em: $<$ http://www.pos.direito.ufmg.br/rbep/index.php/rbep/article/view/57/55>. Acesso em: 25 mar. 2016.

Submissão: 10/01/2016

Aceito para Publicação: 21/06/2016 
